OPEN ACCESS

Edited by:

Daniel Erny,

University of Freiburg Medical Center,

Germany

Reviewed by:

Sharvan Sehrawat,

Indian Institute of Science Education and Research Mohali, India

Keehoon Lee,

Northern Arizona University,

United States

Elena Rampanelli,

Amsterdam University Medical Center

Netherlands

Xin Zhang,

Ningbo University, China

*Correspondence:

Lili Huo

huoliii2020@163.com

Specialty section:

This article was submitted to

Microbial Immunology,

a section of the journal

Frontiers in Immunology

Received: 14 July 2021 Accepted: 28 October 2021 Published: 18 November 2021

Citation:

Zhu W, Wu Y, Liu H, Jiang C and Huo L (2021) Gut-Lung Axis: Microbial Crosstalk in Pediatric Respiratory Tract Infections.

Front. Immunol. 12:741233. doi: 10.3389/fimmu.2021.741233

\section{Gut-Lung Axis: Microbial Crosstalk in Pediatric Respiratory Tract Infections}

\author{
Wenxia Zhu, Yilin Wu, Hui Liu, Caini Jiang and Lili Huo* \\ Shanghai Hospital of Integrated Traditional Chinese and Western Medicine, Shanghai University of Traditional Chinese \\ Medicine, Shanghai, China
}

The gut microbiota is an important regulator for maintaining the organ microenvironment through effects on the gut-vital organs axis. Respiratory tract infections are one of the most widespread and harmful diseases, especially in the last 2 years. Many lines of evidence indicate that the gut microbiota and its metabolites can be considered in therapeutic strategies to effectively prevent and treat respiratory diseases. However, due to the different gut microbiota composition in children compared to adults and the dynamic development of the immature immune system, studies on the interaction between children's intestinal flora and respiratory infections are still lacking. Here, we describe the changes in the gut microbiota of children with respiratory tract infections and explain the relationship between the microbiota of children with their immune function and disease development. In addition, we will provide perspectives on the direct manipulation of intestinal microbes to prevent or treat pediatric respiratory infections.

Keywords: gut microbiota, respiratory tract infection, pediatric, immune system, gut-lung axis

\section{INTRODUCTION}

The intestinal tract is home to about 40 trillion microbiota, and the total number of its genes is about 150 times that of human genes. Given the size of the intestinal flora, it is also known as the "second genome", "second brain", or "gut brain" of the human body. Compared with the microbiota in other parts of the human body, the intestine contains huge bacterial groups and rich species. Therefore, it influences other organs and human body functions in diverse ways. It will soon be commonplace to treat various diseases with consideration of the intestinal microbiota.

\section{INTESTINAL FLORA INVOLVED IN SYSTEMIC IMMUNITY}

The gut microbiota is an increasingly recognized component of the human body that shows dynamic changes with age, region, diet, and medication (1) (Figure 1). Compared with other parts of the body, the intestinal microbiota possesses enormous bacterial taxa and a rich variety of species, and they are relatively easy to be used as targets for biological intervention. The roles of intestinal microbes include stimulating pattern recognition receptors (PRRs) as bacterial antigens, facilitating the maturation of host immune system (2), regulating the secretion of protective immunoglobulin A 


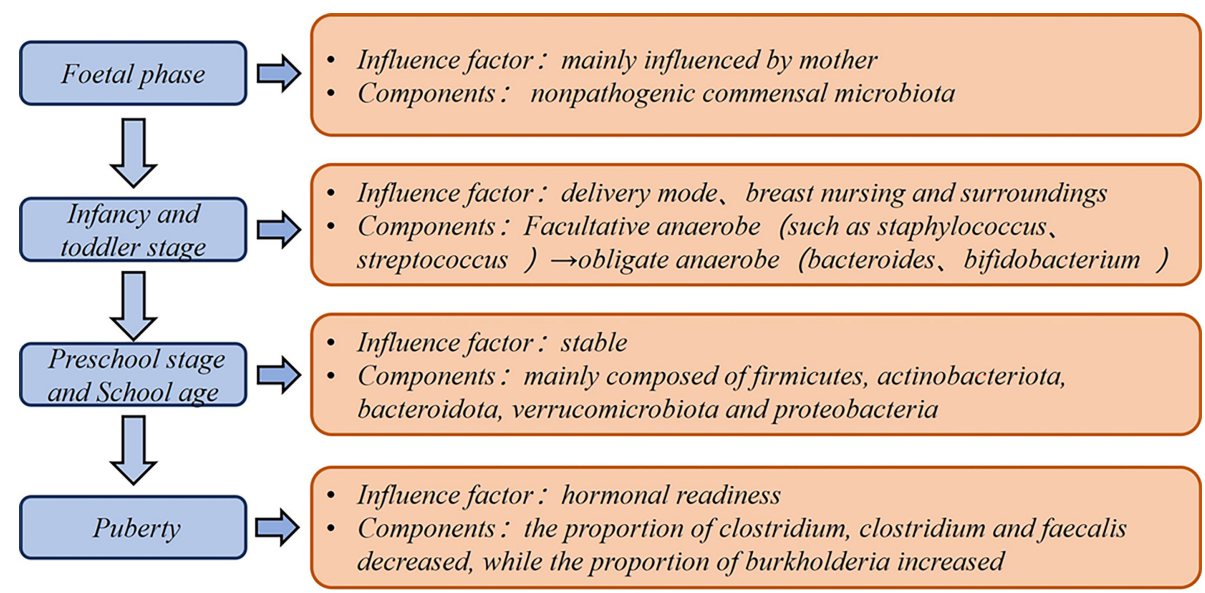

FIGURE 1 | Dynamics of intestinal flora in children.

(IgA) in the intestine (3), affecting the synthesis and transport of neurotransmitters (4), and helping organisms synthesize vitamins and bile acids (5). These events obviously have profound impacts on the host's immune response, nutrition metabolism, and cognitive function (6).

Despite the intestinal partition, the gut microbiota can promote inter-organ communication (5). This is achieved through microbe-produced metabolites. Short-chain fatty acids (SCFAs) are considered significant intestinal microbial metabolites, and acetic acid (C2), propionic acid (C3), and butyric acid (C4) account for approximately $95 \%$ of all SCFAs (7). SCFAs engage in cellular carbohydrate and fatty acid metabolism by regulating cell chromosome acetylation modification status through histone deacetylase inhibition $(8,9)$ or activating cells through the SCFA-G-protein receptor signal transduction pathway. These metabolites can promote immune cell maturation and maintain and regulate intestinal homeostasis in situ, but they also pass through intestinal tract into capillaries and transfer to major organs in the circulation. SCFAs have critical functions in the systemic action of the gut microbiota and play important roles in defense against infection, mitigation of autoimmune diseases, and anti-tumor therapy. In recent years, the description of the gut microbiota and its metabolites involved in respiratory diseases has gradually become more elaborate. With regard to the microbes themselves, microbial surface molecules like lipopolysaccharide (LPS) and lipoteichoic acids can be recognized by the immune system and induce corresponding humoral and cellular immune processes that can improve the host immune system. In controlled experiments on specific pathogenfree (SPM) mice and bacteria-free mice, SPF mice exhibited increased lymphatic tissue activity, more intestinal Peyer's patches, and greater antibody secretion with less susceptibility to systemic inflammation (10-12). The mucosa is the body's first line of defense against external pathogens.

The intestinal microbiota is essential for maturation of mucosal-associated immune tissues (MALT), which can induce the development of gut-associated immune tissues (GALT). Peyer's patches, mesenteric lymph nodes, and isolated lymphoid follicles (ILFs) are important secondary lymphoid tissues of GALT and vital sites for the B cells that produce IgA to neutralize pathogenic microorganisms $(13,14)$. These structures are crucial habitats for IgA-producing plasma cells. In terms of their metabolites, SCFAs could ease microbialinduced allergic lung inflammation by acting on Th2 cells, while antibiotics such as vancomycin increase the incidence of allergic lung diseases by reducing intestinal SCFA levels (15). Moreover, SCFAs have the ability to alleviate pulmonary fibrosis and make patients less susceptible to further infection (16). C2C4 can inhibit neutrophil cytotoxicity (17), and C3 has been reported to inhibit macrophage function in the intestine (18) by inducing the apoptosis of inflammatory dendritic cells (19), thereby affecting immunity in the whole body and all major organs. SCFA affects cells in various ways in different microenvironments. Various organs and microenvironments can induce the differentiation of initial $\mathrm{T}$ cells into effector $\mathrm{T}$ cells or $\mathrm{T}$ regulatory cells $(9,20,21)$. Regarding the effect of SCFAs on B cells, one report indicated that it is associated with shaping intestinal homeostasis and maintaining IgA expression levels in the bronchial-associated mucosal immune system (22). Other recent findings suggest that SCFAs can protect against arthritis by skewing regulatory B cell differentiation (23).

\section{DYNAMIC DEVELOPMENT OF THE PEDIATRIC INTESTINAL FLORA AND IMMUNE SYSTEM}

Although the fetus was previously considered to exist in a sterile uterine environment, the results of a $16 \mathrm{~S}$ ribosomal DNA-based and whole-genome shotgun metagenomic study based of 320 subjects show that the placenta also has unique microbial niche 
that consists of nonpathogenic commensal microbiota (24). A recent study found that a small number of premature babies had placentas containing bacteria of the same origin as their mothers' mouths (25). This suggests that even at the embryonic stage, the fetus is already in contact and exchanging information with microorganisms. In a retrospective analysis of newborn feces, an upward trend appeared in the variety and amount of intestinal microbes (26). The infant gut microbiota shows a rapid increase until 1 year of age. From 1 to 5 years of age, the growth rate of flora diversity decreases and the composition becomes more stable, but their gut microbiota is lower in both number and species compared to adults (27). HIT Chip microarray analysis indicated that the most striking differences between young children and adults are found in Actinobacteria, Bacilli, Clostridium cluster IV, and Bacteroidetes phylum-like groups (28). In terms of dietary habits including fat, protein, sugar, and fiber intake, nutritional intake in infants and older children can lead to dramatic differences in the colonized taxa (29). Before children reach puberty (7-12 years old), their gut microbiota exhibit different functions including vitamin synthesis, amino acid degradation, and oxidative phosphorylation (30).

Compared with adults, the shaping of the pediatric immune system is more dependent on education from the external environment. The gut microbiota provides a window into the immune maturation of newborns. After weaning from breast milk, the intestinal microflora expands and produces related SCFAs, giving the baby a mucosal immune stimulation and promoting immune system maturation $(31,32)$. Bacteria are necessary for ILF development. The addition of solid foods about 2 weeks after weaning can increase bacteria colonization and is thus conducive to enhancing infant gut microbiota integrity (13).

Some hypotheses suggest that children's immune systems are not imperfect, or rather, offer them better protection at an early age. Compared to adults, children's immune systems tend to be more protective to external invasions, but they also generate the corresponding immune response once activated (33). The pediatric immune system is in the process of development, from simple to complex and from tolerant to sensitive. Early adaptive immunity is not well developed, and relies more on the PRRs of innate immunity to recognize danger-related molecular patterns or pathogen-related molecular patterns $(34,35)$. Neonates have fewer neutrophils than adults, and the high level of interleukin (IL)-6 in infants will diminish neutrophil recruitment and thus inflammation $(36,37)$. Natural killer (NK) cells play a prominent role in controlling viral infections, but studies on human fetuses have shown that NK cells are extremely sensitive to transforming growth factor- $\beta$ inhibition, thereby reducing cytotoxicity and interferon $-\gamma$ production $(38,39)$. As for cellular and humoral immunity, infant $\mathrm{T}$ cell immunity skews towards Th2 cells, with reduced Th1 cell differentiation and immune responses (40). Due to less antigenic stimulation, neonates have fewer memory $\mathrm{T}$ cells and memory $\mathrm{B}$ cells than adults (41), and therefore are prone to mild responses following secondary stimulation. In a study of human volunteers of different ages (42), the proportions of CD4 RTE cells, transitional B cells, and CD8 RTE cells decreased with age; furthermore, the vitality of the thymus and bone marrow decreases. Several inflammatory cell subsets including Th1 cells, CD4IL-2 cells, CD8IL-2 cells, and invariant NK T cells are up-regulated with age. In contrast, Th2 and Th17 cells did not show age-related changes.

\section{CROSSTALK BETWEEN GUT MICROBIOTA AND CHILDHOOD RESPIRATORY INFECTIONS}

In adult studies, the gut microbiota can directly regulate the immune function of the lungs (43). In an experiment to detect specific antibodies after influenza virus infection, neomycinsensitive bacteria were shown to be related to the production of immune responses in the lungs (44). Dysbiosis of intestinal microbes can induce mice to have different Th cell responses to influenza virus infection. Th1 and Th2 cells are more controlled by the gut microbiota, with a weaker effect on Th17 cells (45). Follicular helper $\mathrm{T}$ cells are deficient in germ-free mice, leading to a lack of B cell humoral immunity and impaired $\operatorname{Ig} \mathrm{A}^{+}$plasma cell function, which impacts the development and severity of colitis (46). Moreover, antibiotic use can dysregulate the intestinal microbe composition, which triggers the overgrowth of yeasts and more severe pulmonary allergic reactions (47). Common respiratory tract infections in children have been associated with the gut microbiota to some extent $(48,49)$. First of all, children are exposed to the outside world while their microbial colony gradually grows, and the immune system is constantly exposed to foreign antigens, which guide continuous immune system improvement. The gut microbiota shapes the immune system in children, providing constant reserves for the infectious diseases (50).

According to the results of $16 \mathrm{~S}$ rRNA gene sequencing, Lachnospira, Veillonella, Faecalibacterium, and Rothia were reduced in the intestines of children with asthma, and fecal levels of SCFAs and intestinal-liver metabolites were also disordered. These four bacteria are associated with disease progression, and researchers proposed that low abundance of these bacteria contributes to a higher risk of developing asthma before the age of 3 (51). Respiratory syncytial virus (RSV) often causes severe lower respiratory tract infections in infants, but its pathogenesis remains obscure. Some studies have shown that the infant intestinal microbe niche is significantly related to RSV infection severity. The $16 \mathrm{~S}$ rRNA gene sequencing results of the feces of infants infected with RSV showed higher abundance of S247, Clostridiales, Odoribacteraceae, Lactobacillaceae, and Actinomyces in moderately and severely infected patients compared to normal infants. The Moraxellaceae flora decreases in children with severe RSV (52). The correlation between the intestinal microbe niche and respiratory diseases in infants and young children is gradually being revealed for variety of diseases. A study of infant bronchitis (53) revealed that the four dominant bacterial groups in the intestinal tract of normal healthy infants were: Escherichia-dominant profile (30\%), Bifidobacteriumdominant profile (21\%), Enterobacter/Veillonella-dominant 
profile (22\%), and Bacteroides-dominant profile (28\%). However, the predominant taxa in children with bronchitis changed to: Enterobacter/Veillonella-dominant profile (15\%), and Bacteroides-dominant profile (44\%). Researchers hypothesized that the Bacteroides-dominant profile may put infants at a higher risk of developing bronchitis. This lays a theoretical foundation for modifying the gut microbiota to treat or prevent bronchitis. Lei $\mathrm{Li}$ and colleagues (54) reported reduced gut microbiota diversity in pediatric patients with recurrent respiratory tract infections. Conversely, patients were significantly enriched in Firmicutes, Proteobacteria, Bacteroidetes, Actinobacteria, Verrucomicrobia, Tenericutes phylas and Enterococcus, Faecalibacterium, Bifidobacterium, and Eubacterium generas. However, Eubacterium, Faecalibacterium, and Bifidobacterium decreased. Compared to their healthy peers, children with pulmonary tuberculosis had reduced intestinal microbe diversity with enrichment of the proinflammatory bacteria Prevotella and the opportunistic pathogen Enterococcus, and decreases in the probiotics Ruminococcaceae, Bifidobacteriaceae, and Faecalibacterium prausnitzii (55). It can be seen that there is a close relationship between intestinal flora and respiratory tract infection, different respiratory tract infection pathogens can cause different changes in intestinal flora (Table 1).

The direction of the interaction between the gut microbiota and respiratory tract infections remains unclear. Whether fluctuations in the gut microbiota caused by environment, diet, or genetic factors increase the risk of respiratory tract infections, or whether respiratory tract infections skew the gut microbiota requires further investigation. What is certain is that intestinal microbial communities can indeed shape the pediatric immune system. In clinical treatment, altering the intestinal bacteria can indeed treat and prevent severe symptoms of respiratory diseases (60).

After cessation of breastfeeding, the intestinal microflora will expand and produce SCFAs, which will give the infant mucosal immune stimulation and promote immune system maturation (61). Some theories suggest that compared with adults, the pediatric immune landscape is indeed biased towards tolerance. For example, adults develop severe clinical symptoms of SARSCoV-2 (COVID-19) infection, but only very few infected children develop dramatic upper respiratory symptoms (62). Children and adolescents often present with mild or no COVID-19 symptoms. In addition, young children have a very high probability of developing viral respiratory infections but with very low disease symptoms (63). This may be due to the fact that children are constantly undergoing gut microbiota remodeling and have a higher immune tolerance, which helps them resist the devastating effects of cytokine storms on the body.

\section{GUT MICROBIOTA-BASED TREATMENT FOR RESPIRATORY INFECTIONS IN CHILDREN}

The gut microbiota provides protection against respiratory diseases by shaping the immune system. This role is even more pronounced in diseases for which innate immunity is involved in the early stage (64). For example, commensal bacteria transfer therapy can induce the production of neonatal intestinal innate lymphoid cells (ILCs), thereby boosting plasma granulocyte colony-stimulating factor levels and neutrophil numbers and improving IL-17-dependent sepsis tolerance (65). Resistance to respiratory infections can be significantly enhanced by using microbiome-related treatments rather than antibiotic therapies. LPS supplementation can increase the expression of IL-6 and IL-1, as well as the immune response to $E$. coli-induced pneumonia via Toll-like receptor 4 signaling (66). Germ-free mice secreted superfluous IL-10, creating an immunosuppressive microenvironment, which made them more susceptible to bacterial infection. Pretreatment with LPS can decrease IL-10 production and increase the infiltration of neutrophils into infected lungs (67). Intestinal segmented filamentous bacteria are critical in the formation of Th17 immunity against $S$. aureus pneumonia (68). The gut microbiota facilitates the maturation of IL-22 ${ }^{+}$ILC3, offering host resistance to bacterial pneumonia (69). Microbial-based therapies are widely used in clinical trials in the form of probiotics. Compared with conventional antibiotics, intestinal microbiota transplantation can achieve better therapeutic outcomes $(70,71)$. Probiotics and supplements for infants and young children can alter the intestinal microbe composition (72), thereby reducing the risk of respiratory virus infection in premature infants. Supplementing Lachnospira, Veillonella, Faecalibacterium, and Rothia to mice with pneumonia significantly alleviated the symptoms, demonstrating the protective effect and therapeutic potential of

TABLE 1 | Changes in intestinal flora caused by respiratory pathogen infection.

Respiratory

Changes in intestinal flora

References

pathogens

Respiratory syncytial

virus

Influenza virus

Mycoplasma

Streptococcus

pneumoniae

Staphylococcus

aureus

Mycobacterium

tuberculosis

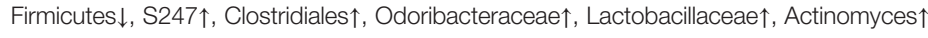

Enterobacter $\uparrow$, Akkermansia $\downarrow$, Desulfovibrio $\downarrow$, Lactobacillus $\downarrow$

Bifidobacterium $\downarrow$, Lactobacillus $\downarrow$, Colibacillus $\uparrow$

Lactobacillus $\downarrow$, Bifidobacterium $\downarrow$, Bacteroidetes $\downarrow$, Colibacillus $\uparrow$

(57)

Total aerobic $\uparrow$, Enterococcus $\uparrow$, Total anaerobic $\downarrow$, Clostridium perfringens $\uparrow$

(59)

Pro-inflammatory bacteria Prevotella $\uparrow$, Opportunistic pathogen Enterococcus $\uparrow$, Probiotics Ruminococcaceae $\downarrow$,

Bifidobacteriaceae $\downarrow$, Faecalibacterium prausnitzii $\downarrow$ 
specific gut microbiota taxa (73). The combination of vitamin $\mathrm{C}$ and probiotics (Lactobacillus acidophilus CUL21, Lactobacillus acidophilus CUL60, Bifidobacterium bifidum CUL20, and Bifidobacterium animalis subsp. lactis CUL34) can effectively lower the infection rate of the upper respiratory tract (74).

\section{FUTURE PERSPECTIVES}

The gut-lung axis theory is gradually being advanced and accepted. Stable development of the intestinal microbiota in children can improve resistance to pathogens that cause respiratory tract infections. As the organ with the largest microbial ecosystem, a healthy intestinal niche often shows rich diversity. During different respiratory diseases, microbes and products in the intestinal tract will turn into morbid types with harmful traits. In the disease state, there is more communication between the intestine and lungs. Mucosa, secretions, $\mathrm{pH}$, and other changes act on target cells and become messengers between the gut and other organs.

In children, the immune system and gut microbiota are undergoing vigorous development. Given that the pediatric gut microbiota is undergoing an integrated developmental process, it is important for us to consider the potential impact of prematurely introducing or eliminating a certain bacteria.

\section{REFERENCES}

1. Lynch SV, Pedersen O. The Human Intestinal Microbiome in Health and Disease. N Engl J Med (2016) 375:2369-79. doi: 10.1056/NEJMra1600266

2. Fulde M, Hornef MW. Maturation of the Enteric Mucosal Innate Immune System During the Postnatal Period. Immunol Rev (2014) 260:21-34. doi: $10.1111 / \mathrm{imr} .12190$

3. Neuman H, Debelius JW, Knight R, Koren O. Microbial Endocrinology: The Interplay Between the Microbiota and the Endocrine System. FEMS Microbiol Rev (2015) 39:509-21. doi: 10.1093/femsre/fuu010

4. Yano JM, Yu K, Donaldson GP, Shastri GG, Ann P, Ma L, et al. Indigenous Bacteria From the Gut Microbiota Regulate Host Serotonin Biosynthesis. Cell (2015) 161:264-76. doi: 10.1016/j.cell.2015.02.047

5. Lavelle A, Sokol H. Gut Microbiota-Derived Metabolites as Key Actors in Inflammatory Bowel Disease. Nat Rev Gastroenterol Hepatol (2020) 17:22337. doi: 10.1038/s41575-019-0258-Z

6. Wilson ID, Nicholson JK. Gut Microbiome Interactions With Drug Metabolism, Efficacy, and Toxicity. Transl Res (2017) 179:204-22. doi: 10.1016/j.trsl.2016.08.002

7. Sun M, Wu W, Liu Z, Cong Y. Microbiota Metabolite Short Chain Fatty Acids, GPCR, and Inflammatory Bowel Diseases. J Gastroenterol (2017) 52:18. doi: 10.1007/s00535-016-1242-9

8. Davie JR. Inhibition of Histone Deacetylase Activity by Butyrate. J Nutr (2003) 133:2485S-93S. doi: 10.1093/jn/133.7.2485S

9. Smith PM, Howitt MR, Panikov N, Michaud M, Gallini CA, Bohlooly-Y M, et al. The Microbial Metabolites, Short-Chain Fatty Acids, Regulate Colonic Treg Cell Homeostasis. Science (2013) 341:569-73. doi: 10.1126/science. 1241165

10. Beaman BL, Gershwin ME, Scates SS, Ohsugi Y. Immunobiology of Germfree Mice Infected With Nocardia Asteroides. Infect Immun (1980) 29:733-43. doi: 10.1128/iai.29.2.733-743.1980

11. Oliveira MR, Tafuri WL, Afonso LC, Oliveira MA, Nicoli JR, Vieira EC, et al. Germ-Free Mice Produce High Levels of Interferon-Gamma in Response to Infection With Leishmania Major But Fail to Heal Lesions. Parasitology (2005) 131:477-88. doi: 10.1017/S0031182005008073
Shifts in gut microbiota early in life or before weaning may provoke an increase in asthma-related immune responses (49). Mild dietary interventions also make sense to treat respiratory infections in children. Given the development of the gut microbiota taxa, we should probably consider using antibiotics with caution. Microbiological intervention strategies should also be considered for children with respiratory infections with marked changes in the gut microbiota due to obesity, complicated enteritis, or immunodeficiency.

\section{AUTHOR CONTRIBUTIONS}

$\mathrm{WZ}$ was in charge of literature retrieval and paper writing. YW, $\mathrm{HL}$, and $\mathrm{CJ}$ were in charge of literature retrieval. $\mathrm{LH}$ was in charge of reviewing the papers. All authors contributed to the article and approved the submitted version.

\section{FUNDING}

Scientific Research Project of Shanghai Municipal Health Commission (202040407); Scientific Research Project of Shanghai Hongkou District Health Commission (HKQ-ZYY2020-01).

12. Tanaka K, Sawamura S, Satoh T, Kobayashi K, Noda S. Role of the Indigenous Microbiota in Maintaining the Virus-Specific CD8 Memory T Cells in the Lung of Mice Infected With Murine Cytomegalovirus. J Immunol (2007) 178:5209-16. doi: 10.4049/jimmunol.178.8.5209

13. Bouskra D, Brézillon C, Bérard M, Werts C, Varona R, Boneca IG, et al. Lymphoid Tissue Genesis Induced by Commensals Through NOD1 Regulates Intestinal Homeostasis. Nature (2008) 456:507-510. doi: 10.1038/nature07450

14. Forbes SJ, Bumpus T, McCarthy EA, Corthesy B, Mantis NJ. Transient Suppression of Shigella Flexneri Type 3 Secretion by a Protective OAntigen-Specific Monoclonal IgA. mBio (2011) 2:e00042-00011. doi: $10.1128 / \mathrm{mBio} .00042-11$

15. Cait A, Hughes MR, Antignano F, Cait J, Dimitriu PA, Maas KR, et al Microbiome-Driven Allergic Lung Inflammation Is Ameliorated by ShortChain Fatty Acids. Mucosal Immunol (2018) 11:785-95. doi: 10.1038/ mi.2017.75

16. Ghorbani P, Santhakumar P, Hu Q, Djiadeu P, Wolever TMS, Palaniyar N, et al. Short-Chain Fatty Acids Affect Cystic Fibrosis Airway Inflammation and Bacterial Growth. Eur Respir J (2015) 46:1033-45. doi: 10.1183/09031936. 00143614

17. Vinolo MA, Rodrigues HG, Hatanaka E, Sato FT, Sampaio SC, Curi R, et al. Suppressive Effect of Short-Chain Fatty Acids on Production of Proinflammatory Mediators by Neutrophils. J Nutr Biochem (2011) 22:84955. doi: 10.1016/j.jnutbio.2010.07.009

18. Chang PV, Hao L, Offermanns S, Medzhitov R. The Microbial Metabolite Butyrate Regulates Intestinal Macrophage Function via Histone Deacetylase Inhibition. Proc Natl Acad Sci U.S.A. (2014) 111:2247-52. doi: 10.1073/ pnas.1322269111

19. Xu S, Liu CX, Xu W, Huang L, Zhao JY, Zhao SM, et al. Butyrate Induces Apoptosis by Activating PDC and Inhibiting Complex I Through SIRT3 Inactivation. Signal Transduct Target Ther (2017) 2:16035. doi: 10.1038/ sigtrans.2016.35

20. Park J, Kim M, Kang SG, Jannasch AH, Cooper B, Patterson J, et al. ShortChain Fatty Acids Induce Both Effector and Regulatory T Cells by Suppression of Histone Deacetylases and Regulation of the mTOR-S6K Pathway. Mucosal Immunol (2015) 8:80-93. doi: 10.1038/mi.2014.44 
21. Furusawa Y, Obata Y, Fukuda S, Endo TA, Nakato G, Takahashi D, et al. Commensal Microbe-Derived Butyrate Induces the Differentiation of Colonic Regulatory T Cells. Nature (2013) 504:446-50. doi: 10.1038/nature12721

22. Ishikawa T, Nanjo F. Dietary Cycloinulooligosaccharides Enhance Intestinal Immunoglobulin A Production in Mice. Biosci Biotechnol Biochem (2009) 73:677-82. doi: 10.1271/bbb.80733

23. Rosser EC, Piper CJM, Matei DE, Blair PA, Rendeiro AF, Orford M, et al. Microbiota-Derived Metabolites Suppress Arthritis by Amplifying ArylHydrocarbon Receptor Activation in Regulatory B Cells. Cell Metab (2020) 31:837-851 e810. doi: 10.1016/j.cmet.2020.03.003

24. Aagaard K, Ma J, Antony KM, Ganu R, Petrosino J, Versalovic J. The Placenta Harbors a Unique Microbiome. Sci Transl Med (2014) 6:237ra265. doi: 10.1126/scitranslmed.3008599

25. Ye C, Katagiri S, Miyasaka N, Kobayashi H, Khemwong T, Nagasawa T, et al. The Periodontopathic Bacteria in Placenta, Saliva and Subgingival Plaque of Threatened Preterm Labor and Preterm Low Birth Weight Cases: A Longitudinal Study in Japanese Pregnant Women. Clin Oral Investig (2020) 24(12):4261-70. doi: 10.1007/s00784-020-03287-4

26. Casaburi G, Duar RM, Brown H, Mitchell RD, Kazi S, Chew S, et al. Metagenomic Insights of the Infant Microbiome Community Structure and Function Across Multiple Sites in the United States. Sci Rep (2021) 11(1):1472. doi: 10.1038/s41598-020-80583-9

27. Cheng J, Ringel-Kulka T, Heikamp-de Jong I, Ringel Y, Carroll I, de Vos WM, et al. Discordant Temporal Development of Bacterial Phyla and the Emergence of Core in the Fecal Microbiota of Young Children. ISME J (2016) 10:1002-14. doi: 10.1038/ismej.2015.177

28. Ringel-Kulka T, Cheng J, Ringel Y, Salojärvi J, Carroll I, Palva A, et al. Intestinal Microbiota in Healthy U.S. Young Children and Adults-a High Throughput Microarray Analysis. PloS One (2013) 8:e64315. doi: 10.1371/ journal.pone.0064315

29. De Filippo C, Cavalieri D, Di Paola M, Ramazzotti M, Poullet JB, Massart S, et al. Impact of Diet in Shaping Gut Microbiota Revealed by a Comparative Study in Children From Europe and Rural Africa. Proc Natl Acad Sci U.S.A. (2010) 107:14691-6. doi: 10.1073/pnas.1005963107

30. Hollister EB, Riehle K, Luna RA, Weidler EM, Rubio-Gonzales M, Mistretta TA, et al. Structure and Function of the Healthy Pre-Adolescent Pediatric Gut Microbiome. Microbiome (2015) 3:36. doi: 10.1186/s40168-015-0101-x

31. Adkins B. Development of Neonatal Th1/Th2 Function. Int Rev Immunol (2000) 19:157-71. doi: 10.3109/08830180009088503

32. Adkins B, Leclerc C, Marshall-Clarke S. Neonatal Adaptive Immunity Comes of Age. Nat Rev Immunol (2004) 4:553-64. doi: 10.1038/nri1394

33. Ghazal P, Dickinson P, Smith CL. Early Life Response to Infection. Curr Opin Infect Dis (2013) 26:213-8. doi: 10.1097/QCO.0b013e32835fb8bf

34. Levy O. Innate Immunity of the Newborn: Basic Mechanisms and Clinical Correlates. Nat Rev Immunol (2007) 7:379-90. doi: 10.1038/nri2075

35. Saso A, Kampmann B. Vaccine Responses in Newborns. Semin Immunopathol (2017) 39:627-42. doi: 10.1007/s00281-017-0654-9

36. Yu JC, Khodadadi H, Malik A, Davidson B, Salles ÉDSL, Bhatia J, et al. Innate Immunity of Neonates and Infants. Front Immunol (2018) 9:1759. doi: 10.3389/fimmu.2018.01759

37. Fielding CA, McLoughlin RM, Colmont CS, Kovaleva M, Harris DA, RoseJohn S, et al. Viral IL-6 Blocks Neutrophil Infiltration During Acute Inflammation. J Immunol (2005) 175:4024-9. doi: 10.4049/jimmunol. 175.6.4024

38. Jost S, Altfeld M. Control of Human Viral Infections by Natural Killer Cells. Annu Rev Immunol (2013) 31:163-94. doi: 10.1146/annurev-immunol032712-100001

39. Ivarsson MA, Loh L, Marquardt N, Kekäläinen E, Berglin L, Björkström NK, et al. Differentiation and Functional Regulation of Human Fetal NK Cells. J Clin Invest (2013) 123:3889-901. doi: 10.1172/JCI68989

40. Dowling DJ, Levy O. Ontogeny of Early Life Immunity. Trends Immunol (2014) 35:299-310. doi: 10.1016/j.it.2014.04.007

41. Adkins B. Heterogeneity in the CD4 T Cell Compartment and the Variability of Neonatal Immune Responsiveness. Curr Immunol Rev (2007) 3:151-9. doi: 10.2174/157339507781483496

42. Carr EJ, Dooley J, Garcia-Perez JE, Lagou V, Lee JC, Wouters C, et al. The Cellular Composition of the Human Immune System Is Shaped by Age and Cohabitation. Nat Immunol (2016) 17:461-8. doi: 10.1038/ni.3371
43. Eribo OA, du Plessis N, Chegou NN. The Intestinal Commensal, Bacteroides Fragilis, Modulates Host Responses to Viral Infection and Therapy: Lessons for Exploration During Mycobacterium Tuberculosis Infection. Infect Immun (2021) 2021:IAI0032121. doi: 10.1128/IAI.00321-21

44. Ichinohe T, Pang IK, Kumamoto Y, Peaper DR, Ho JH, Murray TS, et al. Microbiota Regulates Immune Defense Against Respiratory Tract Influenza A Virus Infection. Proc Natl Acad Sci U.S.A. (2011) 108:5354-9. doi: 10.1073/ pnas. 1019378108

45. Yu B, Dai CQ, Chen J, Deng L, Wu XL, Wu S, et al. Dysbiosis of Gut Microbiota Induced the Disorder of Helper $\mathrm{T}$ Cells in Influenza VirusInfected Mice. Hum Vaccin Immunother (2015) 11:1140-6. doi: 10.1080/ 21645515.2015.1009805

46. Kubinak JL, Petersen C, Stephens WZ, Soto R, Bake E, O'Connell RM, et al. MyD88 Signaling in T Cells Directs IgA-Mediated Control of the Microbiota to Promote Health. Cell Host Microbe (2015) 17:153-63. doi: 10.1016/ j.chom.2014.12.009

47. Noverr MC, Noggle RM, Toews GB, Huffnagle GB. Role of Antibiotics and Fungal Microbiota in Driving Pulmonary Allergic Responses. Infect Immun (2004) 72:4996-5003. doi: 10.1128/IAI.72.9.4996-5003.2004

48. Olszak T, An D, Zeissig S, Vera MP, Richter J, Franke A, et al. Microbial Exposure During Early Life has Persistent Effects on Natural Killer T Cell Function. Science (2012) 336:489-93. doi: 10.1126/science.1219328

49. Russell SL, Gold MJ, Willing BP, Thorson L, McNagny KM, Finlay BB, et al. Perinatal Antibiotic Treatment Affects Murine Microbiota, Immune Responses and Allergic Asthma. Gut Microbes (2013) 4:158-64. doi: 10.4161 /gmic. 23567

50. Abt MC, Osborne LC, Monticelli LA, Doering TA, Alenghat T, Sonnenberg GF, et al. Commensal Bacteria Calibrate the Activation Threshold of Innate Antiviral Immunity. Immunity (2012) 37:158-70. doi: 10.1016/j.immuni. 2012.04.011

51. Simonyte Sjodin K, Vidman L, Ryden P, West CE. Emerging Evidence of the Role of Gut Microbiota in the Development of Allergic Diseases. Curr Opin Allergy Clin Immunol (2016) 16:390-5. doi: 10.1097/ACI.0000000000000277

52. Biesbroek G, Tsivtsivadze E, Sanders EA, Montijn R, Veenhoven RH, Keijser BJ, et al. Early Respiratory Microbiota Composition Determines Bacterial Succession Patterns and Respiratory Health in Children. Am J Respir Crit Care Med (2014) 190:1283-92. doi: 10.1164/rccm.201407-1240OC

53. Hasegawa K, Linnemann RW, Mansbach JM, Ajami NJ, Espinola JA, Petrosino JF, et al. The Fecal Microbiota Profile and Bronchiolitis in Infants. Pediatrics (2016) 138(1):e20160218. doi: 10.1542/peds.2016-0218

54. Li L, Wang F, Liu Y, Gu F. Intestinal Microbiota Dysbiosis in Children With Recurrent Respiratory Tract Infections. Microb Pathog (2019) 136:103709. doi: 10.1016/j.micpath.2019.103709

55. Li W, Zhu Y, Liao Q, Wang Z, Wan C. Characterization of Gut Microbiota in Children With Pulmonary Tuberculosis. BMC Pediatr (2019) 19:445. doi: 10.1186/s12887-019-1782-2

56. Deng L, Shi Y, Liu P, Wu S, Lv Y, Xu H, et al. GeGen QinLian Decoction Alleviate Influenza Virus Infectious Pneumonia Through Intestinal Flora. Biomed Pharmacotherapy (2021) 141:111896. doi: 10.1016/J.BIOPHA.2021. 111896

57. Li C-X, Bai X-H. Effect of Traditional Western Medicine Treatment on Intestinal Flora of Children With Mycoplasma Pneumonia Complicated With Acute Bronchial Asthma. Hebei TRADITIONAL Chin Med (2021) 43 (05):806-10. doi:10.3969/j.issn.1002-2619.2021.05.022

58. Lei M, Zhang X, Yang X, Jing P, Yang M, Yang X. Analysis of Correlation Between Fecal and Alveolar Lavage Fluid Flora of Ventilator-Associated Pneumonia Patients Based on 16S rRNA Sequencing Technology. Zhonghua Wei Zhong Bing Ji Jiu Yi Xue. (2021), 33(2):169-173. doi:10.3760/cma.j.cn121430-20201010-00662

59. Zheng XL, Yang Y, Wang BJ, Wang J, Tang HQ. Synchronous Dynamic Research on Respiratory and Intestinal Microflora of Chronic Bronchitis Rat Model. Chin J Integr Med (2017) 23(3):196-200. doi: 10.1007/s11655-016-2731-7

60. Liu A, Ma T, Xu N, Jin H, Zhao F, Kwok LY, et al. Adjunctive Probiotics Alleviates Asthmatic Symptoms via Modulating the Gut Microbiome and Serum Metabolome. Microbiol Spectr (2021) 9(2):e0085921. doi: 10.1128/ Spectrum.00859-21

61. Al Nabhani Z, Dulauroy S, Marques R, Cousu C, Al Bounny S, Déjardin F, et al. A Weaning Reaction to Microbiota Is Required for Resistance to 
Immunopathologies in the Adult. Immunity (2019) 50:1276-1288 e1275. doi: 10.1016/j.immuni.2019.02.014

62. Bartley JM, Zhou X, Kuchel GA, Weinstock GM, Haynes L. Impact of Age, Caloric Restriction, and Influenza Infection on Mouse Gut Microbiome: An Exploratory Study of the Role of Age-Related Microbiome Changes on Influenza Responses. Front Immunol (2017) 8:1164. doi: 10.3389/ fimmu.2017.01164

63. Esposito S, Daleno C, Prunotto G, Scala A, Tagliabue C, Borzani I, et al. Impact of Viral Infections in Children With Community-Acquired Pneumonia: Results of a Study of 17 Respiratory Viruses. Influenza Other Respir Viruses (2013) 7:18-26. doi: 10.1111/j.1750-2659.2012.00340.x

64. Clarke TB. Early Innate Immunity to Bacterial Infection in the Lung Is Regulated Systemically by the Commensal Microbiota via Nod-Like Receptor Ligands. Infect Immun (2014) 82:4596-606. doi: 10.1128/ IAI.02212-14

65. Deshmukh HS, Liu Y, Menkiti OR, Mei J, Dai N, O'Leary CE, et al. The Microbiota Regulates Neutrophil Homeostasis and Host Resistance to Escherichia Coli K1 Sepsis in Neonatal Mice. Nat Med (2014) 20:524-30. doi: $10.1038 / \mathrm{nm} .3542$

66. Chen LW, Chen PH, Hsu CM. Commensal Microflora Contribute to Host Defense Against Escherichia Coli Pneumonia Through Toll-Like Receptors. Shock (2011) 36:67-75. doi: 10.1097/SHK.0b013e3182184ee7

67. Fagundes CT, Amaral FA, Vieira AT, Soares AC, Pinho V, Nicoli JR, et al. Transient TLR Activation Restores Inflammatory Response and Ability to Control Pulmonary Bacterial Infection in Germfree Mice. J Immunol (2012) 188:1411-20. doi: 10.4049/jimmunol.1101682

68. Gauguet S, D'Ortona S, Ahnger-Pier K, Duan B, Surana NK, Lu R, et al. Intestinal Microbiota of Mice Influences Resistance to Staphylococcus Aureus Pneumonia. Infect Immun (2015) 83:4003-14. doi: 10.1128/IAI.00037-15

69. Gray J, Oehrle K, Worthen G, Alenghat T, Whitsett J, Deshmukh H. Intestinal Commensal Bacteria Mediate Lung Mucosal Immunity and Promote Resistance of Newborn Mice to Infection. Sci Transl Med (2017) 9(376): eaaf9412. doi: 10.1126/scitranslmed.aaf9412

70. Shimizu K, Ogura H, Asahara T, Nomoto K, Morotomi M, Tasaki O, et al. Probiotic/synbiotic Therapy for Treating Critically Ill Patients From a Gut
Microbiota Perspective. Dig Dis Sci (2013) 58:23-32. doi: 10.1007/s10620-0122334-x

71. van Nood E, Vrieze A, Nieuwdorp M, Fuentes S, Zoetendal EG, de Vos WM, et al. Duodenal Infusion of Donor Feces for Recurrent Clostridium Difficile. $N$ Engl J Med (2013) 368:407-15. doi: 10.1056/NEJMoa1205037

72. Partty A, Kalliomaki M, Salminen S, Isolauri E. Infant Distress and Development of Functional Gastrointestinal Disorders in Childhood: Is There a Connection? JAMA Pediatr (2013) 167:977-8. doi: 10.1001/ jamapediatrics.2013.99

73. Arrieta MC, Stiemsma LT, Dimitriu PA, Thorson L, Russell S, Yurist-Doutsch S, et al. Early Infancy Microbial and Metabolic Alterations Affect Risk of Childhood Asthma. Sci Transl Med (2015) 7:307ra152. doi: 10.1126/ scitranslmed.aab2271

74. Olaimat AN, Aolymat I, Al-Holy M, Ayyash M, Abu Ghoush M, Al-Nabulsi AA, et al. The Potential Application of Probiotics and Prebiotics for the Prevention and Treatment of COVID-19. NPJ Sci Food (2020) 4:17. doi: 10.1038/s41538-020-00078-9

Conflict of Interest: The authors declare that the research was conducted in the absence of any commercial or financial relationships that could be construed as a potential conflict of interest.

Publisher's Note: All claims expressed in this article are solely those of the authors and do not necessarily represent those of their affiliated organizations, or those of the publisher, the editors and the reviewers. Any product that may be evaluated in this article, or claim that may be made by its manufacturer, is not guaranteed or endorsed by the publisher.

Copyright (c) $2021 \mathrm{Zhu}, \mathrm{Wu}$, Liu, Jiang and Huo. This is an open-access article distributed under the terms of the Creative Commons Attribution License (CC BY). The use, distribution or reproduction in other forums is permitted, provided the original author(s) and the copyright owner(s) are credited and that the original publication in this journal is cited, in accordance with accepted academic practice. No use, distribution or reproduction is permitted which does not comply with these terms. 